\title{
Fe-Cu Compounds in Dye-Sensitized Solar Cells: Influence of Magnetic Field on Mesoporous Structure
}

\author{
Abdul Hai Alami ${ }^{a} *$, Di Zhang $^{a}$, Camilia Aokal $^{a}$, Jehad Abed $^{b}$, Ideisan Abu Abdoun $^{c}$, Hussain Alawadhi $^{d}$ \\ ${ }^{a}$ Sustainable and Renewable Energy Engineering Department, University of Sharjah, P.O.Box 27272m Sharjah, UAE \\ ${ }^{b}$ Masdar Institute of Technology, Abu Dhabi, United Arab Emirates \\ ${ }^{c}$ Department of Chemistry, University of Sharjah, P.O.Box 27272m Sharjah, United Arab Emirates \\ ${ }^{d}$ Applied Physics Department, University of Sharjah, P.O.Box $27272 \mathrm{~m}$ Sharjah, United Arab Emirates
}

\begin{abstract}
This paper investigates the effect of applying a static and dynamic magnetic field in the process of depositing the $\mathrm{Fe}-\mathrm{Cu}$ compound on the working electrode of a dye-sensitized solar cell (DSSC). Depositing this compound on glass is especially hard due to the unfavorable layer inconsistencies that accompany the utilization of the doctor blade technique and the dissociation of the compound at a temperature of $700^{\circ} \mathrm{C}$, which prevents its ability to be evaporated or sintered beyond that temperature. The $\mathrm{Fe}-\mathrm{Cu}$ compound is appreciably cheaper, relatively simple to produce and is more absorptive $(>81 \%)$ in the Vis-NIR than the standard TiO2 mesoporous material normally used for DSSCs. The high diffusion of the $\mathrm{Fe}$ into the $\mathrm{Cu}$ lattice allows the compound to behave as a semiconductor and is found to have a bandgap of $1.8 \mathrm{~V}$. The sensitizer used in the production of a test cell consisted of a Schiff base dye with a compatible bandgap of $1.68 \mathrm{eV}$ and resulted in more generated photocurrent than its $\mathrm{TiO} 2$ counterpart, which is a promising result for an alternative mesoporous layer in solar cells.
\end{abstract}

Keywords: Ferromagnetic Mesoporous Material, Dye-sensitized Solar Cells, Schiff Base Dyes

\section{Introduction}

Recently, third generation dye sensitized solar cells (DSSC) are seen as a real competitor to conventional silicon based cells and even thin film silicon cells due to their adequate energy conversion efficiency, low cost and ease of manufacturability [1-3].

For even higher energy conversion efficiency values of DSSCs, researchers are improving the performance of individual cell components and, relatable to the work presented here, enhancing the mesoporous nanocrystalline film deposited on the transparent electrode which is known to improve its radiation absorptivity in the UV-Vis ranges on one hand, and enhance the adsorption of dye sensitizers [4-6]. While

${ }^{*}$ Corresponding author

E-mail: aalalami@sharjah.ac.ae

(c) 2016 International Association for Sharing Knowledge and Sustainability

DOI: $10.5383 /$ ijtee.11.01.010 titanium dioxide $\left(\mathrm{TiO}_{2}\right)$ is the most commonly used mesoporous material, a cheaper, recyclable and more optically absorptive alternative is sought, some of which include integrated schiff bases where they are able to achieve large surface areas and efficient electron transfer [7-12]. Another example is to replace it with a mechanically alloyed p-type $\mathrm{Fe}-\mathrm{Cu}$ compound semiconductor that is found to enhance the UV-Vis absorptivity to $81 \%$ compared to that of $\mathrm{TiO}_{2}$ [13]. One challenge is to effectively deposit it on the transparent electrode, as heating the $\mathrm{Fe}-\mathrm{Cu}$ compound above $700{ }^{\circ} \mathrm{C}$ causes its dissociation. By taking advantage of the iron content of the compound, the effects of a magnetic field (either static or dynamic) coupled with heating provides a good surface adhesion with the transparent electrode. The effect of magnetic fields has recently gained noticeable attention due to their ability to enhance 
performance in applications that range from catalysis to electronics and energy [14]. To influence the photocurrent produced in DSSCs, the generation of charge carriers depends on whether or not the cell has been poled by an external magnetic field [15]. The application of magnetic stirring, mentioned in literature, homogenizes $\mathrm{TiO}_{2}$ mixtures before depositing them on transparent electrodes [16]. Ferroelectric-photovoltaic devices, in which a homogeneous photoelectric layer is utilized for radiation absorption, have also been investigated although the main materials of choice were ferroelectric oxides and their efficiency was rather low.

There exist a wide selection of dyes to be used as sensitizers in DSSCs, each with different construction and properties, such as natural, organic and synthetic. Conjugated Schiff base polymers and oligomers have been widely studied recently due to some of their outstanding properties that include: thermal, mechanical, optical, optoelectronic, electronic, and fiber-forming properties [17-21].

In this work, we convey the effect of applying static and dynamic magnetic fields on the optical properties and adsorption capacity of the $\mathrm{Fe}-\mathrm{Cu}$ mesoporous layer, and the impact of any enhancement this has on the performance of the DSSC. The compound is produced using high-energy ball milling where pronounced diffusion of BCC $\mathrm{Fe}$ into FCC $\mathrm{Cu}$ is achieved. This alters the mechanical, optical and electrical properties of the nano-scale quasicrystalline compound. For best spectral absorptivity and compatible bandgap values with the proposed $\mathrm{Fe}-\mathrm{Cu}$ mesoporous layer, suitable organic dyes are also tested and selected. We also introduce the thermally stable conjugated Schiff base compound as a dye in the DSSC.

\section{Experimental}

\subsection{Fe-Cu Powder Synthesis by Ball Milling}

The process of mechanical alloying is performed using a Retsch PM 100 planetary ball mill with a starting amount of $4.5 \mathrm{~g}$ of high purity copper $(<425 \mu \mathrm{m}$, $99.5 \%$ ) and iron ( $\geq 99 \%$ ) powders, as received from the supplier (Sigma-Aldrich) in a $25 \mathrm{ml}$ stainless steel grinding bowl. The target composition of 50:50 of $\mathrm{Fe}$ and $\mathrm{Cu}(\%$ wt.) is pursued at a controlled milling speed of $400 \mathrm{rpm}$. The filling ratio within the bowl was needed to be kept at 5:1, this meant that six 10-mm stainlesssteel balls are used. Milling is carried out for an hour at a time, pausing after each hour to allow for the collection of a few milligrams of the powder for further characterization and testing and also to cool the equipment. It took thirteen hours for the microstructural changes to become small changes, after which the run is terminated.

\subsection{XRD and EDX characterization}

To provide information on the composition and grain structure of the developing solid solution, X-ray diffraction (XRD) patterns are plotted for collected powder samples at two-hour intervals for the length of the experiments. The X-ray patterns are recorded with a Bruker D8 Advance DaVinci multipurpose X-ray diffractometer with $\mathrm{Cu} \mathrm{K \alpha}$ radiation operating at $\lambda=$ $1.5406 \AA, 40 \mathrm{kV}$ tube voltage and $40 \mathrm{~mA}$ current. The lattice parameter was then found using Cohen's method and the grain size by the Full-width half-max (FWHM) analysis with the Hall-Williamson method and Bragg's formula.

\subsection{Fe-Cu Deposition on ITO}

After the desired microstructure of the single phase $\mathrm{FCC}(\mathrm{Cu})$ compound is formed and verified by XRD and EDX, it is deposited on a glass slide over an indium-tin oxide (ITO) conductive layer. This was performed using doctor blading technique, where the $\mathrm{Fe}-\mathrm{Cu}$ compound, mixed in glycerol, is spread onto four identical ITO glass slides using a glass rod to obtain a homogenous thin film. The deposited film is then sintered using three plate heaters, two of which had magnetic stirring turned on with one glass slide placed at the center of each, while the third plate heater had two of the remaining slides share the central position, hence sharing the same applied static magnetic field. The samples are left on the heaters for thirty minutes at $230-250^{\circ} \mathrm{C}$. Then, two slides, one from a stirred magnetic field effect and the other from a static magnetic field effect, were used to manufacture the DSSC. The remaining had their powders transferred onto carbon tape for absorptivity and SEM analysis.

\subsection{SEM Micrographs}

A scanning electron microscope (SEM) and the coupled energy dispersive X-ray spectrometer (EDX) are used to examine fused pieces of the material collected after thirteen hours of milling time. The SEM is a VEGA3 $\mathrm{XM}$ by TESCAN, operating at $5 \mathrm{kV}$, while the EDX analysis is conducted with both map and point modes at the same operating voltage; the former was acquired during 3 minutes while the latter was from four different spots of the sample during 30 s live time.

\subsection{Optical Properties (Absorptivity)}

After 13 hours of milling, spectral measurements of absorption in the ultraviolet, visible and near-infrared (UV-Vis-NIR) regions were carried out on the powders within an integrating sphere attached to two Maya 2000Pro high-resolution spectrometers (OceanOptics). One dedicated for the UV wavelength range $(200-380 \mathrm{~nm})$, and the other dedicated to the Vis-NIR range (375-850 $\mathrm{nm}$ ), both having a resolution of $0.2 \mathrm{~nm}$ and 300 lines per $\mathrm{mm}$ diffraction gratings and $10-\mu \mathrm{m}$ entrance slit. The 
signals are transported via a fiber optic cable 2-m long, and of a $200-\mu \mathrm{m}$-core diameter. The integrating sphere (OceanOptics ISP-REF, with a sample aperture of 0.4 inch) has a built-in tungsten halogen light source (Ocean Optics LS-1-LL) and is capable of measuring specular and diffuse reflectance. A reference surface in the form of a reflection standard (B0071519) is used to store baseline absorptance $(0 \%)$ spectra to facilitate comparison between the various compositions.

\subsection{Solar Cell Manufacturing and Testing}

Two cells were constructed with each $\mathrm{Fe}-\mathrm{Cu}$ compound variations deposited on the photoelectrode to quantify the effects of magnetic patterning of the $\mathrm{Fe}-\mathrm{Cu}$ on its effectiveness as a mesoporous material in DSSCs. A homogenous paste was prepared from the two compounds and then spread as a thin layer by employing the doctor blading technique on ITO coated glass (1525 /sq., used as received from Sigma-Aldrich) as outlined in section 2.3. The electrolyte used is the $I^{-} / I_{3}^{-}$ classic redox electrolyte prepared from $127 \mathrm{mg}$ iodine crystals, $830 \mathrm{mg}$ potassium iodide and $10 \mathrm{ml}$ ethylene glycol which are mixed thoroughly until completely dissolved. The electrolyte will be the diffusion medium for ionic species between the working photoelectrode prepared as above and the counter electrode made up of a pure copper sheet $(99.5 \%$ copper sheet $1.2 \mathrm{~mm}$ thickness, used as received from Sigma-Aldrich) with carbon deposits on an area of $2.5 \times 2.5 \mathrm{~cm}$ to enhance the surface area and consequently the conductivity. The injection of electrons and diffusion of ionic species, or the operation mechanism, of DSSCs is well explained and documented in literature for the $I^{-} / I_{3}^{-}$redox electrolyte [40]. The testing of the solar cell to measure its power conversion efficiency (PCE), fill factor (FF) and IV characteristics are conducted using a solar simulator Xenon Arc Lamps setup, capable of providing irradiance between $0.1-1$ suns (up to $1367 \mathrm{~W} / \mathrm{m}^{2}$ ). The setup was used to provide a constant irradiation on the cells, and was kept at a vertical distance of $30 \mathrm{~cm}$ at 1.5 $\mathrm{AM}$ and $25{ }^{\circ} \mathrm{C}$. The cell characterization is conducted using VSP-300 potentiostat from Biologic with a potential resolution of $1 \mu \mathrm{V}$ and a control voltage of \pm 10 $\mathrm{V}$ up to $\pm 48 \mathrm{~V}$. The voltage was varied at a rate of 10 $\mathrm{mV} / \mathrm{s}$ and the current was recorded at each point until the measured voltage reached the open circuit voltage, $V_{\mathrm{OC}}$.

\section{Results and Discussion}

\subsection{XRD and EDS characterization of the Milled Powder}

The desired quasicrystalline phase was formed after thirteen hours of ball milling, as confirmed by the XRD analysis of Figure 1 (a), and the resulting grain size is shown in Figure 1 (b), showing a nominal size of around $10 \mathrm{~nm}$.

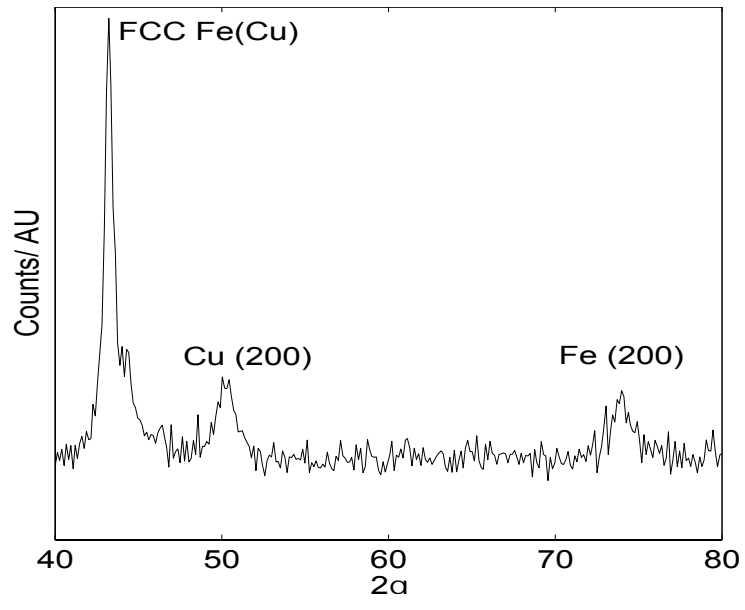

(a)

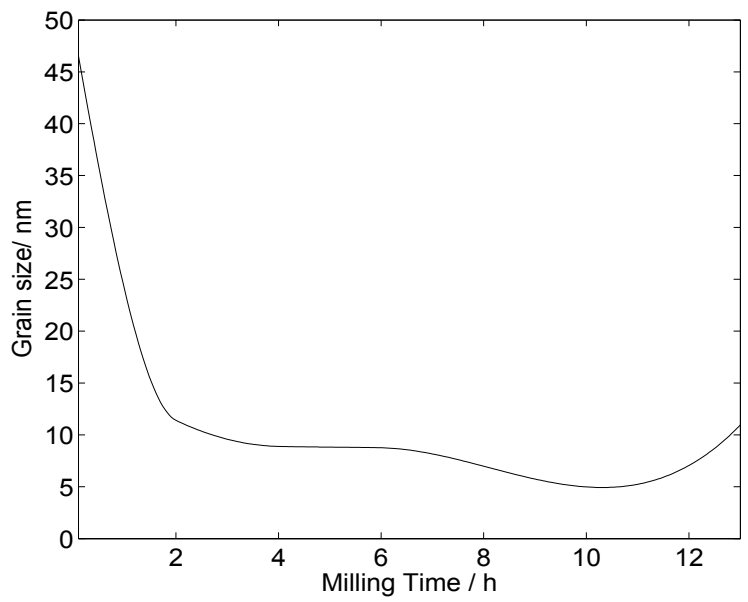

(b)

Fig.1. (a) XRD Plot of the Fe-Cu Compound and (b) the Resulting Grain Size

\subsection{Fe-Cu Deposition on ITO and SEM Image}

Clear differences between the resulting patterns are seen in Figure 2 when comparing the SEM images of $\mathrm{Fe}-\mathrm{Cu}$ compounds deposited on ITO glass with and without magnetic stirring. A rougher surface is visible in the magnetically stirred sample due to the radial motion of the grains in response to the applied rotating magnetic field. Specimens subject to the static magnetic field show a clustering of the grains, while others under the dynamic magnetic field exhibit an apparent shift of these grains where significant agglomeration is seen, which increased the layer thickness during the radial motion of the particles in response to magnetic stirring. 


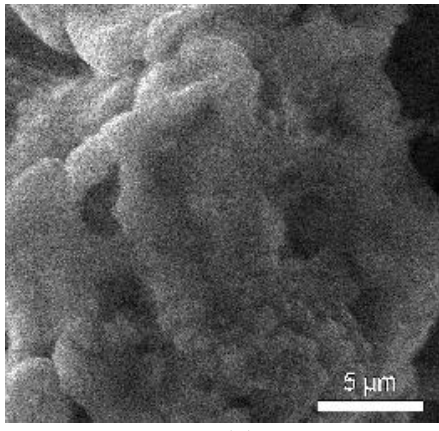

(a)

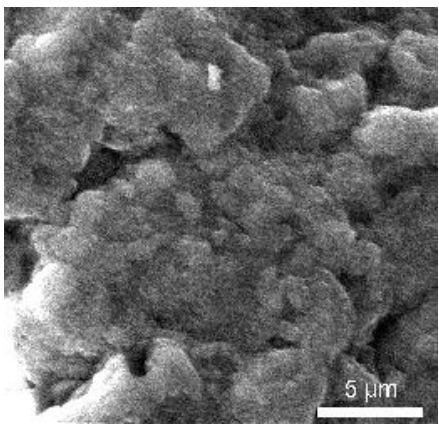

(b)

Fig. 2. SEM Micrographs for Fe-Cu Structure at 10kx Magnification (a) with Static Magnetic Field and (b) with Magnetic Stirring

During the sintering/stirring process and whenever magnetic stirring is present, a visual inspection of the resulting layer reveals the presence of concentric circles, as seen in Figure 3 (b).

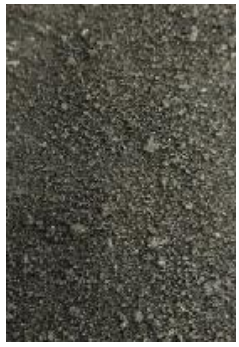

(a)

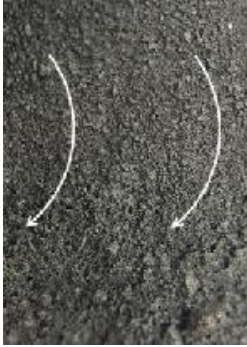

(b)
Fig. 3. Micrographs for Fe-Cu Structure (a) without Magnetic Stirring and (b) with Magnetic Stirring, Showing a Concentric Circles Pattern

\subsection{Optical Absorptivity of Fe-Cu Compound}

The figures below show the optical absorptivity results where Figure 4 (a) and (b) account for the UV and VisNIR ranges, respectively. A behavior similar to that of $\mathrm{TiO}_{2}$ in the UV range although the absorptivity peak is shifted from around $350 \mathrm{~nm}$ to around $410 \mathrm{~nm}$ as seen in Figure 4 (a).

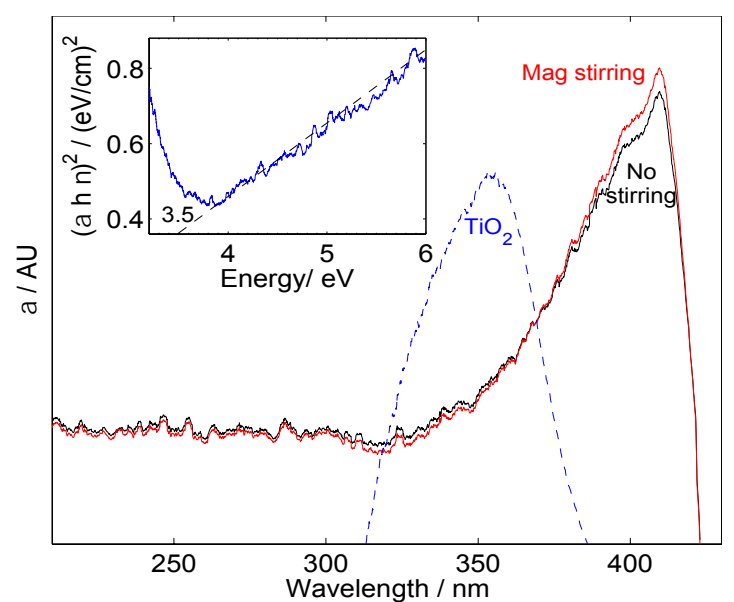

(a)

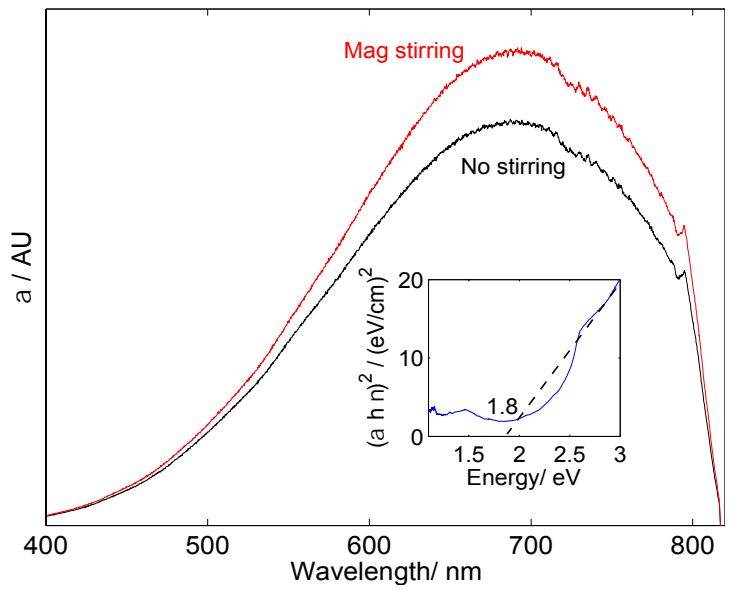

(b)

Fig. 4. The Optical Absorptivity shown For two Specimens of $\mathrm{Fe}-\mathrm{Cu}$ compound, one magnetically stirred while being heated and another only heated in the (a) UV range and (b) Vis-NIR ranges with the optical bandgap (inset)

The absorptivity is then observed to grow steadily in the Vis-NIR ranges to reach a peak at around $680 \mathrm{~nm}$ for both specimens of magnetic and non-magnetic stirring effects, as shown in Figure 4 (b). The magnetic stirring shows stronger absorption magnitudes at the edge of the visible region, where the area under the absorptivity curve is $15 \%$ larger than that without stirring, indicating an enhancement in absorptivity due mainly to the alterations observed in the microstructure, and seen in the SEM graphs of Figure 2.

Given the shape of the absorptivity, the bandgap of the compound is of interest to be calculated, and thus the absorptivity results were substituted into Tauc equation and the resulting intercept with the abscissa, which gives the bandgap energy is found to be $1.8 \mathrm{eV}$ in the Vis-NIR range, which is a value consistent with ones found for the compound in previous investigations [13] and shows good compatibility with the Schiff base dye used. 


\subsection{Characterization of the Solar Cell}

The employed $\mathrm{Fe}-\mathrm{Cu}$ (with static magnetic field) and $\mathrm{TiO}_{2}$ working photoelectrodes on DSSCs were fabricated and characterized side-by-side. Nevertheless, a relatively fast degradation of the device was observed even though the measurement was performed immediately after cell assembly. Insufficient adhesion of the $\mathrm{Fe}-\mathrm{Cu}$ film sample to the ITO substrate by magnetic stirring was found to be insufficient for cell assembly. The degradation in DSSC may be due to the electrolyte degrading or the fast desorbing of the dye from the working electrode [22]. As a result, partial current density-voltage (J-V) characteristics for both cells were obtained. From Figure 5 that shows the extrapolated I-V characteristics, it can be seen that the $\mathrm{Fe}-\mathrm{Cu}$ DSSC demonstrated a much larger short-circuit current density of $0.052 \mathrm{~mA} / \mathrm{cm}^{2}$, compared to that of $\sim 0.002 \mathrm{~mA} / \mathrm{cm}^{2}$ of $\mathrm{TiO}_{2}$ device. The significantly increased photocurrent of the $\mathrm{Fe}-\mathrm{Cu}$ can be attributed to both the unique property of $\mathrm{Fe}-\mathrm{Cu}$ material and the magnetic field effect: with the static magnetic field, the $\mathrm{Fe}-\mathrm{Cu}$ layer can be aligned in a single direction (pointing away from the substrate plane), forming a more ordered microstructure which is beneficial for dye absorption; furthermore, the $\mathrm{Fe}-\mathrm{Cu}$ with increased roughness shows higher absorptivity than $\mathrm{TiO}_{2}$ in the visible region, as shown in Fig. 4 (b), which can contribute to the light trapping of the attached dye for photocurrent generation. Differently, the open-circuit voltage $\left(V_{\mathrm{OC}}\right)$ of $\mathrm{Fe}-\mathrm{Cu}$ is only $\sim 0.018 \mathrm{~V}$, which is approximately an order smaller than the reference $\mathrm{TiO}_{2}$ device $(0.26 \mathrm{~V})$. The considerable loss in $V_{\mathrm{OC}}$ may arise from the much larger contact resistance of the $\mathrm{Fe}-\mathrm{Cu}$ electrode (with a larger thickness) than $\mathrm{TiO}_{2}$. Consequently, more precise control on the thickness of the layer by a different deposition method is highly preferable for further applications of the $\mathrm{Fe}-\mathrm{Cu}$ material.

\section{Conclusion}

In this work, an investigation was carried out on the influence of a magnetic field on the production of a homogenous mesoporous layer made of the $\mathrm{Fe}-\mathrm{Cu}$ quasicrystalline compound by testing its spectral absorption and its performance in a dye-sensitized solar cell. The bandgap of this compound, which exhibits semiconducting performance, was calculated from absorptivity results to be $1.8 \mathrm{eV}$. A homogenous layer with excellent light absorption characteristics in the VisNIR ranges resulted from the magnetic field applied that was used to assist in the proper arrangement of the compound on the transparent electrode throughout the deposition process. The Schiff base sensitizing dye used was chosen because it has a compatible bandgap of 1.68 $\mathrm{eV}$, and the assembled cell gave a current density of around $0.05 \mathrm{~mA} / \mathrm{cm}^{2}$ although its open circuit voltage was around $0.02 \mathrm{~V}$. A high throughput process of mechanical alloying in a ball mill was used to make the $\mathrm{Fe}-\mathrm{Cu}$ nano-scale homogenous compound, which has a potential to replace $\mathrm{TiO} 2$ as a cheaper, recyclable mesoporous layer with better light harvesting characteristics.

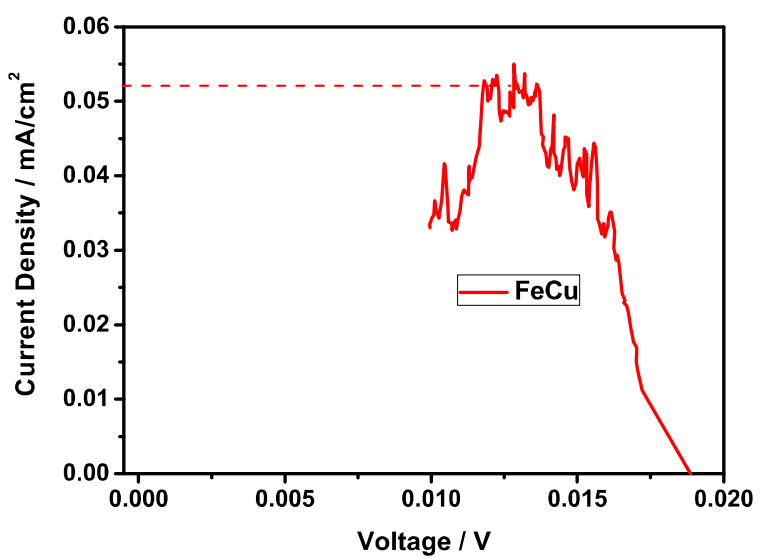

(a)

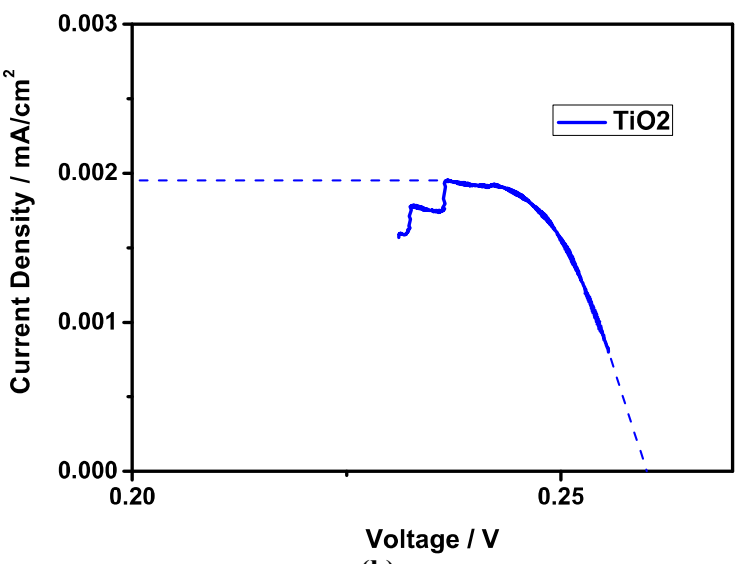

(b)

Fig. 5. Characteristic Curves for the (a) $\mathrm{Fe}-\mathrm{Cu}$ Based Cell (with Static Magnetic Field) and (b) $\mathrm{TiO}_{2}$ Based Cell

\section{References}

[1] O'Regan B, Grätzel M. A low-cost, highefficiency solar cell based on dye-sensitized colloidal $\mathrm{TiO} 2$ films. Nature. 1991;353(6346):737-740.

[2] Nazeeruddin M, Péchy P, Grätzel M. Efficient panchromatic sensitization of nanocrystalline TiO2 films by a black dye based on a trithiocyanato-ruthenium complex. Chemical Communications. 1997;(18):1705-1706.

[3] Green M, Emery K, Hishikawa Y, Warta W, Dunlop E. Solar cell efficiency tables (version 46). Prog Photovolt: Res Appl. 2015;23(7):805812.

[4] Yella A, Lee H, Tsao H, Yi C, Chandiran A, Nazeeruddin $M$ et al. Porphyrin-Sensitized Solar Cells with Cobalt (II/III)-Based Redox Electrolyte Exceed 12 Percent Efficiency. Science. 2011;334(6056):629-634. 
[5] Chiba Y, Islam A, Watanabe Y, Komiya R, Koide N, Han L. Dye-Sensitized Solar Cells with Conversion Efficiency of $11.1 \%$. Jpn J Appl Phys. 2006;45(No. 25):L638-L640.

[6] Wang L, Shi Y, Zhang H, Bai X, Wang Y, Ma T. Iron oxide nanostructures as highly efficient heterogeneous catalysts for mesoscopic photovoltaics. J Mater Chem A. 2014;2(37):15279.

[7] Aegerter M, Schmitt M, Guo Y. Sol-gel niobium pentoxide coatings: Applications to photovoltaic energy conversion and electrochromism. International Journal of Photoenergy. 2002;4(1):1-10.

[8] Bakhshayesh A, Bakhshayesh N. Enhanced performance of dye-sensitized solar cells aided by $\mathrm{Sr}, \mathrm{Cr}$ co-doped $\mathrm{TiO} 2$ xerogel films made of uniform spheres. Journal of Colloid and Interface Science. 2015;460:18-28.

[9] Mir N, Salavati-Niasari M. Preparation of TiO2 nanoparticles by using tripodal tetraamine ligands as complexing agent via two-step solgel method and their application in dyesensitized solar cells. Materials Research Bulletin. 2013;48(4):1660-1667.

[10] Masjedi M, Mir N, Noori E, Gholami T, Salavati-Niasari M. Effect of Schiff base ligand on the size and the optical properties of $\mathrm{TiO} 2$ nanoparticles. Superlattices and Microstructures. 2013;62:30-38.

[11]Liu J, Wang Y, Sun D. Enhancing the performance of dye-sensitized solar cells by benzoic acid modified $\mathrm{TiO} 2$ nanorod electrode. Renewable Energy. 2012;38(1):214-218.

[12] Navaneethan M, Archana J, Arivanandhan M, Hayakawa Y. Functional properties of aminepassivated $\mathrm{ZnO}$ nanostructures and dyesensitized solar cell characteristics. Chemical Engineering Journal. 2012;213:70-77

[13] Alami A, Alketbi A, Almheiri M. Synthesis and Microstructural and Optical Characterization of $\mathrm{Fe}-\mathrm{Cu}$ Metastable Alloys for Enhanced Solar Thermal Absorption. Energy Procedia. 2015;75:410-416.
[14] Li F, Xin L, Liu S, Hu B. Direct measurement of the magnetic field effects on carrier mobilities and recombination in tri-(8hydroxyquinoline)-aluminum based lightemitting diodes. Appl Phys Lett. 2010;97(7):073301.

[15] Cai F, Wang J, Yuan Z, Duan Y. Magneticfield effect on dye-sensitized $\mathrm{ZnO}$ nanorodsbased solar cells. Journal of Power Sources. 2012;216:269-272.

[16] Xiao-Hua L, Shu-Qin Y, Yu Z, Zhi-An W, Ning-Kang H. Effects of Different Dispersion Methods on the Microscopical Morphology of TiO 2 Film. Chinese Physics Letters. 2007;24(12):3567-3569.

[17] Grigoras M, Catanescu CO. Imine oligomers and polymer. J Macromol Sci- Pure Appl Chem Polym C 2004;44:131-73.

[18] Jenekhe SA, Yang CJ, Vanherzeele H, Meth JS. Cubic nonlinear optics of polymer thin films. Effects of structure and dispersion on the nonlinear optical properties of aromatic Schiff base polymers. Chem Matter 1991;3:985-7.

[19] Diaz FR, Moreno J, Tagle LH, East GA, Radic D. Synthesis, characterization and electrical properties of polyimines derived from selenophene. Synth Met 1999;100:187-94.

[20] Morgan PW, Kwolek SL, Pletcher TC. Aromatic azomethine polymers and fibers. Macromolecules 1987;20:729-39.

[21] Ragimov AV, Mamedov BA, Gasanova SG. New efficient dielectric and antistatic materials based on oligoaminophenols. Polym Int 1997;43:343-6.

[22] L. Ke, S. B. Dolmanan, L. Shen, P. K. Pallathadk, Z. Zhang, D. M. Y. Lai, H. Liu, Degradation mechanism of $\mathrm{ZnO}$-based dyesensitized solar cells, Solar Energy Materials and Solar Cells, Volume 94, Issue 2, February 2010, Pages 323-326 